\title{
A Review of China's Rural Tourism Research
}

\author{
Tengyu Wang ${ }^{1, *}$ Zhaoyun $\mathrm{Li}^{2}$ Haitao You ${ }^{1}$ \\ ${ }^{1}$ School of History and Culture, Linyi University, Linyi, Shandong, China \\ ${ }^{2}$ Experimental Management Center, Linyi University, Linyi, Shandong, China \\ *Corresponding author. Email: 252337249@qq.com
}

\begin{abstract}
Rural tourism is an important means of developing the rural economy and improving the rural economic. Therefore, it is of great significance to summarize the research on rural tourism in China. Starting from the basic concept of rural tourism, this paper summarizes the literature on rural tourism in China, and concludes that the current research on rural tourism in China focuses on five aspects: the concept of rural tourism, culture and travel integration, rural tourism and rural revitalization strategy, rural tourism dynamic mechanism, and rural tourism stakeholders. On the basis of literature analysis and research, some suggestions are put forward for the future research and development of rural tourism.
\end{abstract}

Keywords: Rural tourism, Literature review, Research prospects.

\section{INTRODUCTION}

The rapid development of economy and technology has made people's lives faster and more convenient, and changed the way of life in the past. While enjoying the dividends brought by economic development, urban residents are also under pressure from many aspects, such as the destruction of the urban environment, fast-paced life, and high work pressure. Therefore, a low-cost and highly feasible method is needed for urban residents to choose to relieve pressure. In this context, starting from the middle of the last century, rural tourism began to appear in economically developed countries and showed its strong vitality and vitality. Rural tourism provides a feasible path to achieve the goal of poverty alleviation and adjustment of industrial structure in rural areas, and it has been the first to be confirmed by practice in developed areas [1]. Wang Bing (1999) believes that the emergence and development of rural tourism in my country is the product of a combination of many factors, such as market demand, national policy support, and the stimulation of successful foreign cases [2]. As an effective way to promote the development of rural economy in China, rural tourism has attracted the attention and research of many scholars.

\section{OVERVIEW OF RURAL TOURISM IN CHINA}

\subsection{The Development History of Rural Tourism in China}

Chinese scholars generally believe that the starting point for the development of rural tourism in China is the first Litchi Festival held in Shenzhen in 1988. The success of the Litchi Festival has played a strong leading and exemplary role. Under the guidance of interests, various regions have begun to follow suit, and China's rural tourism has slowly entered the development stage [3]. After the "Rural Tourism Year" held in 2006, rural tourism has entered a new stage of development, which also has a lot to do with the weekend system. As an important way to promote the economic development of rural areas, rural tourism has received more and more attention from the country. China has also continuously introduced relevant policies to promote the development of rural tourism. The following "Table 1 " is the summary of the rural tourism policies issued by China in the past 10 years ("Table 1"). 
Table 1. Government documents on rural tourism

\begin{tabular}{|c|c|c|c|}
\hline Time & Department & Document & Relevant content \\
\hline 2013. 3 & $\begin{array}{l}\text { China National } \\
\text { Tourism } \\
\text { Administration }\end{array}$ & $\begin{array}{l}\text { "Outline of the } \\
\text { Twelfth Five-Year } \\
\text { Plan for China's } \\
\text { Tourism" }\end{array}$ & $\begin{array}{l}\text { The overall development of China's tourism industry is showing a } \\
\text { good trend, and the next development should pay more attention to } \\
\text { solving the problem of the mismatch between the national tourism } \\
\text { demand and the supply of tourism products. In particular, it is } \\
\text { necessary to increase the protection and development of rural } \\
\text { leisure tourism resources. }\end{array}$ \\
\hline 2015. 1 & State Council & $\begin{array}{l}\text { "Several Opinions on } \\
\text { Promoting the } \\
\text { Reform and } \\
\text { Development of } \\
\text { Tourism" }\end{array}$ & $\begin{array}{l}\text { Strengthen the protection of characteristic resources, plan the } \\
\text { development process, design and formulate scientific and } \\
\text { reasonable development plans, and develop rural tourism } \\
\text { resources on the basis of protection. }\end{array}$ \\
\hline 2016 & State Council & $\begin{array}{l}\text { Central Document } \\
\text { No. } 1\end{array}$ & $\begin{array}{l}\text { Promote the development of rural tourism and leisure tourism. } \\
\text { Innovate the development of rural tourism and strengthen the } \\
\text { protection of natural landscapes and cultural heritage in rural areas. }\end{array}$ \\
\hline 2016. 9 & $\begin{array}{l}\text { China National } \\
\text { Tourism } \\
\text { Administration }\end{array}$ & $\begin{array}{l}\text { "Eight Action Plans } \\
\text { for Poverty } \\
\text { Alleviation by Rural } \\
\text { Tourism" }\end{array}$ & $\begin{array}{l}\text { The five major tasks of the rural tourism poverty alleviation project } \\
\text { have been determined and the eight major actions of rural tourism } \\
\text { poverty alleviation have been promoted. }\end{array}$ \\
\hline 2017.7 & $\begin{array}{l}\text { Planning and } \\
\text { Finance } \\
\text { Department of } \\
\text { National } \\
\text { Tourism } \\
\text { Administration }\end{array}$ & $\begin{array}{l}\text { "Action Plan to } \\
\text { Promote the Quality } \\
\text { and Upgrade of Rural } \\
\text { Tourism } \\
\text { Development (2017)" }\end{array}$ & $\begin{array}{l}\text { Based on the reality of the countryside, make full use of local } \\
\text { characteristic tourism resources, dig deep into cultural factors, and } \\
\text { create unique rural tourism products. Form their own brand and } \\
\text { characteristics. }\end{array}$ \\
\hline 2017.9 & $\begin{array}{l}\text { General Office } \\
\text { of Ministry of } \\
\text { Agriculture }\end{array}$ & $\begin{array}{l}\text { "Notice on Promoting } \\
\text { the Implementation of } \\
\text { Policies for the } \\
\text { Development of } \\
\text { Leisure Agriculture } \\
\text { and Rural Tourism" }\end{array}$ & $\begin{array}{l}\text { Promulgate policies that are conducive to the development of rural } \\
\text { industries, attach importance to the adjustment of rural industrial } \\
\text { structure, use rural tourism to drive the development of the tertiary } \\
\text { industry, and guide the sustainable and healthy development of the } \\
\text { rural economy. }\end{array}$ \\
\hline
\end{tabular}

Source: Foresight Economist's website; the official website of Culture and Tourism of the People's Republic of China

\subsection{Status Quo of Rural Tourism Research in China}

There are many journals related to rural tourism in China, including tourism, geography, economics, social sciences and other disciplines and categories, but geography and tourism are the main positions. The author takes the research literature included in CNKI (China National Knowledge Internet) as the main research object, and searches the related literature in CNKI under the title of "Rural Tourism" and reads them. During the retrieval process, it is found that the relevant articles are mainly included in the journal "Tourism Tribune", "Progress in Geography", "Journal of Beijing International Studies University", "Areal Research and Development", "Human Geography", "Scientia Geographica Sinica", "Economic Geography" and journals of various universities. Through the search, 32,734 related documents were obtained. After the second screening of these documents according to the number of citations, 215 documents were selected for key reading and research. Among them, by searching and reading articles with a large number of downloads and citations, it is found that the research on rural tourism focuses on the following aspects: research on the concept and type of rural tourism, rural tourism stakeholders, research on sustainable development of rural tourism, integration of cultural and tourism, rural revitalization strategy and research on rural tourism, etc.

China's rural tourism started late, but now theoretical research and practical experience have achieved good results, and its development research 
can also be divided into different stages. The first is the initial embryonic stage of China's rural tourism in the late 1980s, mostly based on basic content, such as: the explanation of the definition of rural tourism, the study of rural tourism resources, and the prospects for the future development of rural tourism in China. Ling Shen (1990) believed that China's rural tourism resources have great advantages of diverse natural scenery and long history and culture [4]. Du Jiang (1999) used the ideas and theories of sustainable development to point out that in the follow-up process of rural tourism development, attention should be paid to supply and demand, as well as the host-guest interaction in rural tourism activities [5]. Second, after 2000, China began to enter the stage of comprehensive development of urban and rural economy. At this stage, rural tourism research began to combine actual cases to put forward opinions on the design and operation of rural tourism products, and the research content was more abundant. Zou Tongqian (2005) studied the development model of rural tourism in China by comparing Chengdu farmhouses and Beijing folk villages, and believed that the key factors for the success of rural tourism operations are as follows: the administrative power to rely on scenic spots, family services, monopoly of the distribution of tourist sources, and a good location. The probability of successful rural tourism is the highest in the 1-2 hours drive from the city center [6]. Hu Wenhai (2008) took Chizhou City, Anhui Province as an example to analyze the status quo of rural tourism development [7]. Third, in the past ten years, the research on rural tourism has mostly focused on solving the problems exposed in the process of practice, such as: sustainable development, how to display the unique culture of the village, and coordination of stakeholders.

\section{THE CURRENT RESEARCH FOCUS OF RURAL TOURISM IN CHINA}

\subsection{The Concept of Rural Tourism}

Xiao Youxing (2001) believed that rural tourism is the use of different landscapes, customs, culture, production and lifestyles in rural areas to attract urban residents and provide urban residents with corresponding tourism products and services [8]. Xiao Youxing mainly gave the definition from the perspective of rural resources and rural uniqueness; Wang Bing (1999) believed that rural tourism mainly relies on agriculture and related matters in rural areas to integrate viewing, learning, entertainment and other activities into a tourism activity method [2]. This concept highlights the content of agriculture in rural areas; Ma Bo (1996) believed that rural tourism is a type of activity in rural communities, with unique production patterns, life styles and pastoral scenery as objects [9]; Du Jiang and Xiang Ping (1999) were unique in that they pay attention to the consumption of rural tourism activities. Rural tourism is a tourism method that meets the needs of urban residents with unique scenery and activities [14]. Scholars have different emphasis on the definition of the concept of rural tourism, but there are several common points in the definition of rural tourism: the first is that it is based on the rural space environment, which is different from the city; the second is that it has the unique cultural characteristics of rural areas; the third is that it is closely integrated with the rural traditional primary industry.

\subsection{Research on Cultural Factors of Rural Tourism}

Huang Zhenfang (2018) pointed out that against the background of China's rapid industrialization and urbanization, the phenomenon of hollowing out in rural areas is inevitable, the traditional agricultural planting industry is weak, and the rural culture is gradually declining without inheritance. This series of problems in turn restrict the development of rural areas [10]. Therefore, how to better protect and use rural culture has become an important topic for scholars. Gui Ladan and Tang Wei (2016) believed that protecting and making good use of the characteristic culture and folklore of rural areas is an important way to promote rural development. Among them, a good organic combination of culture and tourism is an effective way to promote poverty alleviation in rural area, creating regionally recognizable tourism products based on local characteristics, and promoting the construction of beautiful new rural areas [11]. Liu Yutang (2020) elaborated on the increasingly serious homogeneity of rural tourism driven by interests at this stage, which has become an important obstacle restricting the development of rural tourism to branding and boutique [12]. The key to how to break the bottleneck period in rural areas lies in improving the rural core competitiveness. Yin Zhenhua (2004) pointed out that it is necessary to strengthen the "cultural perfusion" of rural tourism development. He advocated that it is necessary to dig deeper into the connotation of rural culture, regain the people's 
cultural memory of the village, and create a cultural space with regional characteristics to improve recognition [13]. Xie Yanjun proposed in 1999 that the development of rural tourism must be guided by a correct tourism development concept [14], which fully reflects the uniqueness of rural areas, especially the cultural connotation, and embodies the soul pillar role of culture in tourism.

\subsection{Rural Tourism and Rural Revitalization Strategy}

In the report of the 19th National People's Congress in October 2017, the strategy of rural revitalization was put forward, and the resolution of the "three agricultural" issues was the top priority of the whole party's work. Judging from the current research situation, the research mainly focuses on the following two aspects: one is the research on the relationship between rural revitalization strategy and rural tourism. Li Xiaoying and Huang Weiyan (2019) believed that there are both mutual promotion and mutual restriction between the two. Mutual promotion is manifested in the fact that the two essentially share common development concepts and development goals, and the development of rural tourism promotes the implementation of rural revitalization strategies; Mutual restriction is manifested in the inevitability of ecological destruction in the development of rural tourism, and the impact of modernization on rural traditional civilization; in turn, the rural revitalization strategy will restrict the development of rural tourism if the system is not perfect [15]. Yin Yuan and Li Xiaoqin (2018) analyzed that the relationship between the two is mainly mutual promotion. The development of rural tourism in rural areas has advantages that other industries do not possess, such as economic development and optimization of rural industrial structure on the basis of minimal environmental damage. The rural revitalization strategy is also an important policy support for the development of rural tourism [16]. The author believes that the relationship between the two is mutually promoting at this stage in China, and the phenomenon of mutual restriction is still at a relatively weak stage. The second is how to innovate the development model of rural tourism under the background of the rural revitalization strategy. Wang Chen (2018) proposed the "collectivized rural tourism development model" and explained through case studies what positive impacts it can have on the rural revitalization strategy [17]. From the beginning of the development of rural tourism, the development of individual households was the main form, and the forms of picking by individual farmers and farmhouses were the main forms. Rural tourism continues to develop in depth and collectivize rural tourism, such as Xidi and Hongcun in Anhui. Concentrating collective efforts to develop rural tourism is conducive to brand building and creation; Gao Yuan (2018) proposed that the sustainable development of rural tourism should pay attention to the consumption needs of tourists, resource development should be adapted to local conditions, and the innovation of business models should achieve high-quality sustainable development and help the realization of the rural revitalization strategy [18], which needs to take the road of sustainable development, that is, to obtain the golden mountains and silver mountains, but also to protect the green waters; Yang Yuting (2018) and others conducted research on the development path of rural tourism resources against the background of rural revitalization strategy, highlighting the rationality, protection and integrity of resource development [19]; Qi Quanming (2018) analyzed the feasibility and specific measures of taking leisure agriculture as the development and utilization of rural idle homestead under the strategy of rural revitalization [20]. Liao Cairong (2017) believed that to better promote the "five-inone" development of rural areas, more attention should be paid to scientific and reasonable planning, and development and construction should be carried out under the guidance of reasonable planning to achieve efficient and sustainable development [21].

\subsection{Research on the Dynamic Mechanism of Rural Tourism}

Through the literature review, the following theories concerning the research on the dynamic mechanism of rural tourism are summarized. Yang Jun (2006) pointed out that the four factors of "demand, supply, marketing and support network" are important contents that affect the forward power system of rural tourism. When analyzing the factors affecting the development of rural tourism, the above factors should be systematically analyzed [22]. Demand is an important condition for the development of rural tourism. Without demand, rural tourism cannot obtain economic income without the development of the market. Supply meets demand. Through transactions, people's demand is turned into a real force for economic development. Marketing and support network to promote better function of demand and supply; Ye 
Hong (2007) believed that the government's policy orientation has a greater influence among the many dynamic factors. Based on the actual situation of rural tourism development and management and China's basic national conditions, the government's policy support plays an important role. At this stage, the Chinese government has given good policy support to the "three agricultural" issues, which has played a good role in promoting the development of rural tourism [23]; Zhang Xiaoming and Bao Jigang (2009) believed that the advancement and development of rural tourism is a combination of various internal and external factors. It involves many aspects in economic, political, cultural, social and other fields [24]. According to specific case studies, some scholars believed that the key role in the dynamic mechanism of rural tourism development is still the market, making full use of the market's supply-demand relationship, and doing a good job of managing and controlling risks [25]; some scholars believed that Chinese "homesickness" is a driving force that cannot be ignored in promoting the development of rural tourism. General Secretary Xi Jinping also pointed out that "homesickness" is the "local complex" that every Chinese has [26].

\subsection{Research on Stakeholders of Rural Tourism}

The concept of "stakeholders" was proposed. Most scholars believe that it was first proposed in the 1960s. Researchers at Stanford College believed that corporate stakeholders mainly include shareholders, customers, employees, suppliers, and communities [27]. At this stage, the Chinese tourism industry generally believes that the main stakeholders are: local residents, developers, governments and tourists. Zhu Hua (2006) pointed out that the development of rural tourism requires relevant enterprises to inject funds to complete development and management matters, and people cannot ignore the interests of the residents living and producing here [28]. Hu Wenhai (2009) pointed out that the development of rural tourism requires a clear development plan and an adjustment mechanism to coordinate the interests of all parties, and the development model should be a participatory model to increase the participation of rural residents. Dai Zeguang and $\mathrm{Hu}$ Mingyong (2009) applied game theory to community participation in rural tourism activities, and pointed out that government organizations should play a coordinating role. At the same time, it is necessary to clarify the interest distribution mechanism of the stakeholders, so that the dynamic game can develop in the direction of a healthy order. Yu Ping (2010) analyzed that in the development of rural tourism, further development is restricted due to insufficient participation of residents and uneven distribution of benefits. Therefore, it is of great significance to improve the benefit distribution system, and the community empowerment needs to be enhanced from the aspects of social empowerment, individual empowerment and institutional empowerment, so as to ensure the harmony between the stakeholders and jointly promote the development of the scenic spot. Bao Jigang and Sun Jiuxia (2008) proposed that environmental protection is part of the sustainable development of rural tourism, and it is also particularly important to coordinate the relationship between the various entities. To truly highlight the dominant status of the community, it is a necessity to first conduct restraint management at the institutional level and carry out institutional empowerment [29].

\section{RESEARCH WEAKNESSES AND PROSPECTS}

\subsection{Research Weaknesses}

By summarizing the development of rural tourism in China and the research results, it is concluded that there are three shortcomings at this stage:

First, the theoretical research is relatively simple. The initial stage of rural tourism research is mainly based on the definition of concepts. With the continuous development of China's rural tourism practice, the research focus has also changed. At this stage, theoretical research lacks depth, which is mainly manifested in the fact that some contents only study the causes of superficial phenomena, without conducting in-depth research on the internal mechanism. The reason for this situation is that, on the one hand, the development of practice is not sufficient, and many things have not been fully exposed to increase the difficulty of theoretical research; on the other hand, the development of rural tourism is in the stage of rapid development in practice, and market demand makes the research direction more inclined to practice. Therefore, in the follow-up research and development of rural tourism, it is necessary to strengthen the research of theoretical depth.

Second, the focus of research is mostly on the macro-qualitative, and there is a lack of deeper micro-research. In the research process, the 
research on rural eco-tourism, sustainable development and other macro issues are concentrated, such as the classification of rural tourism, the dynamic mechanism of rural tourism, and the classification of development and development models. In recent years, Chinese scholars have also realized this problem, and the research on rural tourism has gradually shifted to the micro level. However, some researches on micro-contents promote its development, such as the consumption behavior characteristics of rural tourists.

Third, the pertinence and practicality of theoretical research is not strong. The current research in China mainly stays in the qualitative description, analysis and classification of the phenomena that appear in rural tourism, which leads to weak pertinence and practical operation. Therefore, in the future research, it is a must for people to pay more attention to adopting quantitative methods to analyze actual cases, to obtain specific data and conclusions that are conducive to improving the actual operation, so as to better promote the development of rural tourism practice.

\subsection{Prospects}

In view of the current deficiencies and the problems exposed in practice, this article believes that the future research on rural tourism should be carried out from the following aspects.

The first is the targeted development and research of rural tourism resources on the basis of fully investigating the needs of the tourism market. The use of rural areas has formed unique tourism resources in the course of its thousands of years of development. It is necessary to discover these unique tourism resources, create distinctive rural tourism with logos, strengthen the protection and development of unique tourism resources in rural tourism, and create exclusive rural tourism brand.

The second is the transformation of development concepts, with more emphasis on cultural characteristics and sustainable development. With the continuous development of society, tourists have changed their demand for rural tourism. In the past, simple visits and excursions have been difficult to meet the needs of tourists. In addition, the country is also vigorously promoting the integrated development of culture and tourism at this stage, making the tourism industry more core attractive, creating a deeper attraction for tourists, and better promoting the rural tourism to take the road of sustainable development. The upgrading and innovation of rural tourism should be the focus of the further research.

The third is to focus on the use of innovative thinking. After decades of development in rural tourism, a bottleneck period has appeared. There are more and more defects are constantly exposed such as homogenized rural tourism scenic spots, inadequate services, imperfect infrastructure construction, etc. How to innovate new development ideas, new development paths and development methods, break through the bottleneck period, and promote the development of rural tourism in a better direction has become the focus of future research.

\section{CONCLUSION}

Based on the literature analysis and research of rural tourism in China, in this paper, some suggestions are put forward for the future research and development of rural tourism. With a view to arouse the attention of relevant experts and scholars in China, putting forward more and better management and operation measures to promote the faster and better development of China's rural tourism.

\section{AUTHORS' CONTRIBUTIONS}

Tengyu Wang was responsible for the article writing; Zhaoyun Li was responsible for topic selection and article modification; Haitao You provided literature and supplemented part of the paper.

\section{ACKNOWLEDGMENTS}

I would like to send my great gratitude to my tutor Zhaoyun Li.

\section{REFERENCES}

[1] He Jingming, A Study on Rural Tourism Overseas [J]. Tourism Tribune, 2003, 18(1): 76-80. (in Chinese)

[2] Wang Bing, Viewing the Prospect of China's Agrotourism by Contrasting Agrotourism in Foreign Countries with That in Our Country [J]. Tourism Tribune, 1999 (02): 34-38+75. (in Chinese) 
[3] Wang Degang, Rural Ecotourism Development and Management [M]. Ji'nan: Shandong University Press, 2010. (in Chinese)

[4] Ling Shen, On the Development of Rural Tourism Resources in China [J]. Agricultural Modernization, 1990 (05): 18-21+47. (in Chinese)

[5] Du Jiang, Xiang Ping, Thoughts on the Sustainable Development of Rural Tourism [J]. Tourism Tribune, 1999 (01): 15-18+73. (in Chinese)

[6] Zou Tongqian, On the Development Pattern of Rural Tourism in China - Comparative Studies on the Development between the Happy-farmer in Chengdu and the Folklorehamlet in Beijing [J]. Tourism Tribune, 2005(03): 63-68. (in Chinese)

[7] $\mathrm{Hu}$ Wenhai, Research on the Development of Rural Tourism Based on Stakeholders - A Case Study of Chizhou City, Anhui Province [J]. Issues in Agricultural Economy, 2008(07): 84-88. (in Chinese)

[8] Xiao Youxing, Ming Qingzhong, Li Songzhi, On the Concept and Types of Rural Tourism [J]. Tourism Science, 2001(03): 11-13. (in Chinese)

[9] Ma Bo, Conception of Developing Rural Tourism in Guanzhong Area. Theory and Practice of Regional Tourism Development [M]. Jiangsu People's Publishing House, 1996. (in Chinese)

[10] Huang Zhenfang, Huang Rui, Research Progress on Rural Culture in the Context of Rapid Urbanization and Tourism Development: Academic Debate and Future Research Prospects, 2018(02): 5-21. (in Chinese)

[11] Gui Ladan, Tang Wei, A Study on Taking Targeted Measures in Tourism Poverty Alleviation Model of Culture and Tourism Integration Countryside: Taking Lin Zhai village in Guangdong Province as an Example [J]. Northwest Population Journal, 2016(02): 66-70. (in Chinese)

[12] Liu Yutang, Gao Ruixia, Research on the Core Competitiveness of Rural Tourism from the Perspective of Cultural and Tourism Integration [J]. Theory Monthly, 2020(01): 92-100. (in Chinese)
[13] Yin Zhenhua, New Ways to Develop China's Village Tourism [J]. Tourism Tribune, 2004(05): 39-43. (in Chinese)

[14] Xie Yanjun, Rural Tourism Development with Tourist Cities as Source Markets [J]. Research on Financial and Economis Issues, 1999(10): 80-82. (in Chinese)

[15] Li Xiaoying, Huang Weiyan, Rural Revitalization and Rural Tourism Development [J]. China Journal of Commerce, 2019(08): 211-212. (in Chinese)

[16] Yin Yuan, Li Xiaoqin, Internal Response and Path Selection of Rural Tourism Under the Background of Rural Vitalization Strategy [J]. Journal of Chinese Academy of Governance, 2018(05): 183-187+194. (in Chinese)

[17] Wang Chenguang, The Influence and Enlightenment of the Development Model of Collectivized Rural Tourism on Rural Revitalization Strategy [J]. Shandong Social Science, 2018(05): 34-42. (in Chinese)

[18] Gao Yuan, The Development of Rural Tourism to Boost Rural Revitalization Should Grasp the "Four Characteristics" [J]. China Development Observation, 2018(3): 51-53. (in Chinese)

[19] Yang Yuting, He Jianjia, Liu Jusheng, Research on the Evolution of Rural Tourism Resources Development Path under the Background of "Rural Revitalization Strategy" - Based on the Perspective of Evolutionary Game [J]. Enterprise Economy, 2018(1): 2430. (in Chinese)

[20] Qi Quanming, Rural Revitalization Strategy and the Development and Utilization of Rural Idle Homesteads _ Taking Leisure Agriculture and Internet Agriculture as Examples [J]. Theory Monthly, 2018(7): 123129. (in Chinese)

[21] Liao Cairong, Chen Meiqiu, The Theoretical Logic, Scientific Connotation and Achieving Methods of Rural Revitalization Strategy [J]. Journal of Agri-Forestry Economics and Management, 2017(06): 102-109. (in Chinese)

[22] Yang Jun, A Study of the Driving Factors of Rural Tourism in China and the Systematic Optimization [J]. Tourism Science, 2006, 20(4): 7-11. (in Chinese) 
[23] Ye Hong, The Research Institute of the Dynamic Mechanism of Rural Tourism Development Takes the Development of Rural Tourism in Chengdu as an Example [J]. Rural Economy, 2007(10): 79-82. (in Chinese)

[24] Zhang Xiaoming, Bao Jigang, Tourism Development and Rural Vicissitudes: the Hypothesis of "Origin-Dynamics" [J]. Tourism Tribune, 2009, 24(6): 19-24. (in Chinese)

[25] Huang Wei, Meng Fei, Xiao Shuliang, An Empirical Study of the Impetus for the Development of Rural Tourism Industry from the Perspective of Targeted Poverty Alleviation - Taking Wuling Mountain Area as an Example [J]. Journal of Minzu University of China, 2017(6): 57-68. (in Chinese)

[26] Huang Jie, Soil Complex, Family Complex and Agritourism Development [J]. Thinking, 2003, 29(05): 24-26. (in Chinese)

[27] Dan Ba, Chen Kaijian, Zhu Siying, Evolutionary Game Analysis of Stakeholders in Rural Tourism Community [J]. Rural Economy, 2019(12): 143-150. (in Chinese)

[28] Yu Ping, Analysis of Sustainable Development of Rural Tourism Based on Community Empowerment $[\mathrm{J}]$. Journal of Harbin University of Commerce (Social Science Edition), 2010(2): 93-96. (in Chinese)

[29] Bao Jigang, Sun Jiuxia, Community Participation in Tourism of Yubeng Village: Means of Participation and its Significance for Empowerment [J]. Tourism Tribune, 2008, 1(1): 58-65. (in Chinese) 